\title{
Necrotizing Enterocolitis after Octreotide Treatment in a Preterm Newborn with Idiopathic Congenital Chylothorax
}

\author{
Mehmet Buyuktiryaki, ${ }^{1 *}$ Mehmet Yekta Oncel, ${ }^{2}$ Nilufer Okur, ${ }^{1}$ Turan Derme,,${ }^{1}$ Serife Suna Oguz ${ }^{1}$ \\ 1 Division of Neonatology, Zekai Tahir Burak Maternity Teaching Hospital, Ankara, Turkey. \\ 2 Division of Neonatology, Department of Pediatrics, Katip Çelebi University, İzmir, Turkey.
}

\begin{abstract}
Octreotide, a somatostatin analogue, has been used for the management of patients with refractory chylothorax. Side effects related to the gastrointestinal system associated with octreotide are necrotizing enterocolitis (NEC) and focal intestinal perforation. NEC is the most common and dangerous gastrointestinal emergency in premature infants. We present the development of necrotizing enterocolitis after octreotide treatment in a preterm infant with idiopathic congenital chylothorax which settled after discontinuation of octreotide.
\end{abstract}

Key words: Congenital chylothorax; Octreotide; Necrotizing enterocolitis; Preterm

Correspondence*: Mehmet Buyuktiryaki MD, Zekai Tahir Burak Maternity Teaching Hospital, Division of Neonatology, Altındağ, 06230, Ankara, Turkey.

E-mail: mbuyuktiryaki@yahoo.com

(C) 2017, Buyuktiryaki, et al

Submitted: 29-07-2017

Accepted: 29-08-2017

Conflict of Interest: None

Source of Support: Nil

This is an open-access article distributed under the terms of the Creative Commons Attribution License, which permits unrestricted use, distribution, and reproduction in any medium, provided the original work is properly cited.

\section{INTRODUCTION}

Chylothorax is defined as accumulation of lymph in the pleural space and it is the most common cause of pleural effusion in newborns with respiratory distress.[1] The diagnosis is made in the pleural fluid with triglyceride level $>110 \mathrm{mg} / \mathrm{dl}$ and total cell count $>1000 / \mathrm{ml}$ with $>80 \%$ lymphocyte inclusion.[2]

The treatment of chylothorax includes conservative management or surgery. Intravenous octreotide has been increasingly used for the management of chylothorax.[3] However, various side effects related to the use of octreotide have been reported.[4,5]

NEC is a known side effect of octreotide.[4,5] We herein report a preterm neonate with congenital chylothorax who developed NEC with the treatment of chylothorax.

\section{CASE REPORT}

A 2450 gram male infant was born at $34^{\text {th }}$ weeks, via cesarean section due to fetal distress to a 28 years old mother, G3P3. Pregnancy was complicated by polyhydramnios and bilateral pleural effusion. There was no sign of hydrops fetalis. Neonate's APGAR score was 4/7. Since the spontaneous breathing trials were unsuccessful, newborn was intubated and monitored in NICU. Arterial blood gas analysis showed pH 7.28, pCO2 62 $\mathrm{mmHg}, \mathrm{HCO} 3$ 17.8, BE -8.3. On chest $\mathrm{x}$-ray, bilateral pleural fluid was observed for which bilateral chest tubes were placed followed by $150 \mathrm{cc}$ fluid drainage. Pleural fluid analysis was as follows: LDH $97 \mathrm{U} / \mathrm{L}$, cholesterol $28 \mathrm{mg} / \mathrm{dl}$, triglycerides $9 \mathrm{mg} / \mathrm{dl}$, leukocyte count $1500 / \mathrm{mm} 3$ with $100 \%$ lymphocytes. After the pleural fluid was drained, newborn was extubated with improved ventilation and at postnatal $2^{\text {nd }}$ hour, was placed on nasal

Citation: Buyuktiryaki M, Oncel MY, Okur N, Derme T, Oguz SS. Necrotizing enterocolitis after octreotide treatment in a preterm newborn with idiopathic congenital chylothorax. APSP J Case Rep. 2017; 8:34. 
CPAP. Oral feeding with $20 \mathrm{cc} / \mathrm{kg} /$ day breast milk was initiated at postnatal $6^{\text {th }}$ hour. Nasal CPAP was discontinued at postnatal $16^{\text {th }}$ hour. Feeding was optimized gradually. On second day in total $80 \mathrm{cc}$, and $3^{\text {rd }}$ day $60 \mathrm{cc}$ chylous fluid was drained. Right chest tube was removed on the 3rd postnatal day. On postnatal day 4, 10 cc chylous fluid was drained from the left chest tube. Pleural fluid analysis yielded triglyceride level at $368 \mathrm{mg} / \mathrm{dl}$, leukocyte count of $14900 / \mathrm{mm} 3$ with $82 \%$ lymphocytic predominance. Oral feeding was replaced by medium chain triglyceride containing formula.

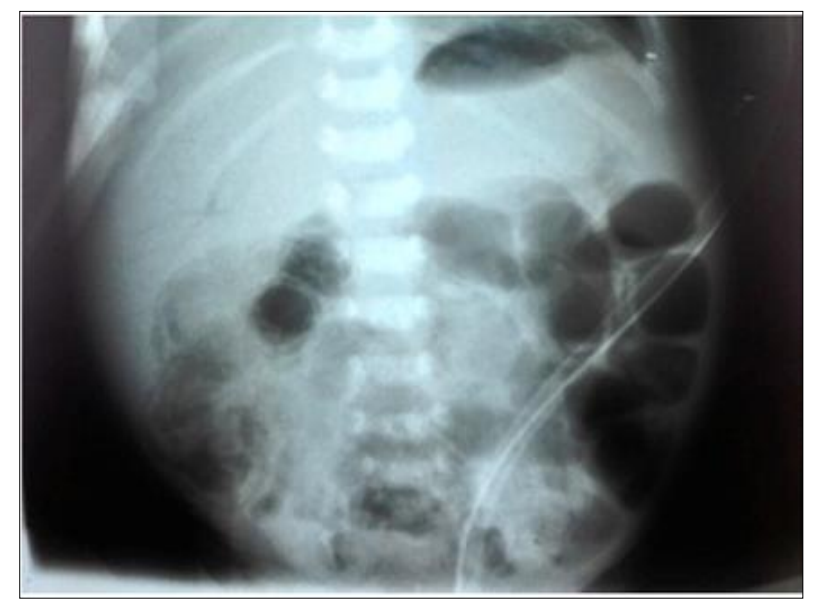

Figure 1: Pneumatosis intestinalis in right lower quadrant and air in the portal vein is observed.

On postnatal day 6 , left chest tube continued to drain 40 cc chylous fluid so patient was started on $1 \mathrm{mcg} / \mathrm{kg} / \mathrm{h}$ intravenous octreotide which was subsequently followed by decreased drainage. On the $4^{\text {th }}$ day of therapy, patient was noted to have abdominal distention, tenderness, and bilious emesis. Upright abdomen film revealed pneumatosis intestinalis in the right lower quadrant and air was seen in the intrahepatic portal vein (Fig.1). Simultaneously, abdomen ultrasound was performed which showed dilated bowel loops with minimal free fluid in the pelvis. No umbilical catheter was placed at that time or before stage II B NEC development.

As treatment, primarily octreotide infusion and oral feeding were discontinued. Total parenteral nutrition was initiated. He was initiated on orogastric decompression and was then started on antibiotics; vancomycin and amikacin.

Three days following cessation of octreotide treatment, abdominal distention decreased. Medium-chain triglycerides (MCT) including formula feeding was initiated on postnatal day 17, which was followed with full oral feeding in 6 days. During his following hospital course, chylothorax did not recur. Patient was discharged on postnatal day 30 and no further problems were encountered at 2 month follow up clinic visit.

\section{DISCUSSION}

The somatostatin analogue octreotide, reduces pancreatic secretion, gall bladder and gastrointestinal motility and reduces intestinal blood flow by vasoconstriction of the splanchnic vessels. [4,5] With these effects on the octreotide gastrointestinal tract, fat absorption in the thoracic duct and lymphatic flow is reduced.[4] Octreotiderelated side effects include NEC, focal intestinal perforation, intraventricular hemorrhage, periventricular leukomalacia, seizures, hypotension, and rash.[4,5] Octreotide induced NEC cases are extremely rare.

Few cases with transient chylothorax in patients with aortic coarctation (after brief cardiopulmonary resuscitation and after cardiopulmonary surgery) developed NEC after octreotide treatment within 72 hours, however some cases of neonates with congenital hyperinsulinemia have also been reported to develop NEC due to octreotide treatment within 1 to 3 days.[6,7]

Our patient was given a lower dose of octreotide than what was reported in the literature and developed NEC on 4th day of treatment which is in accordance to the published literature. We associated the NEC findings to the octreotide treatment since it appeared within 90 hours the treatment was initiated and subsided quickly (48 hours) after the treatment was discontinued. Octreotide decreases the mesenteric blood flow, and it can result in NEC. Octreotide indeed causes a significant degree of diminished blood flow on celiac, superior and inferior mesenteric artery.[8]

In conclusion, premature newborns on octreotide treatment for congenital chylothorax are at high risk for NEC development and should be carefully monitored. On suspicion the therapy should be discontinued as we did in our patient.

Consent: Authors have submitted signed consent form from legal guardians of the patient for use of clinical material in this manuscript. The Consent form is available with Editorial office.

Authors' Contribution: All authors contributed equally in concept, literature review, and drafting of the manuscript and approved the final version of this manuscript. 


\section{REFERENCES}

1. Dubin PJ, Kind IN, Gallagher PG. Congenital chylothorax. Curr Opin Pediatr. 2000; 12:505-9.

2. Buttiker V, Fanconi S, Burger R. Chylothorax in children: guidelines for diagnosis and management. Chest. 1999;116:682-7.

3. Das A, Shah PS. Octreotide for the treatment of chylothorax in neonates. Cochrane Database Syst Rev. 2010;9:CD006388.

4. Foo NH, Hwang YS, Lin CC, Tsai WH. Congenital chylothorax in a late preterm infant and successful treatment with octreotide. Pediatr Neonatol. 2011;52:297-301.

5. Testoni D, Hornik CP, Neely ML, Yang Q, McMahon AW, Clark $\mathrm{RH}$, et al. Best pharmaceuticals for children act -
Pediatric Trials Network Administrative Core Committee. Safety of octreotide in hospitalized infants. Early Hum Dev. 2015;91:387-92.

6. Mohseni-Bod H, Macrae D, Slavik Z. Somatostatin analog (octreotide) in management of neonatal postoperative chylothorax: is it safe? Pediatr Crit Care Med. 2004;5:356-7.

7. Laje P, Halaby L, Adzick NS, Stanley CA. Necrotizing enterocolitis in neonates receiving octreotide for the management of congenital hyperinsulinism. Pediatr Diabetes. 2010; 11:142-7.

8. Moreira-Pinto J, Rocha P, Osório A, Bonet B, Carvalho F, Duarte $\mathrm{C}$, et al. Octreotide in the treatment of neonatal postoperative chylothorax: report of three cases and literature review. Pediatr Surg Int. 2011;27:805-9. 